\title{
Virtual Learning for Human Respiratory System Via Non-Immersive VR (V-HURESYS): An Evaluation
}

\author{
Nurul Hidayah Mat Zain ${ }^{1,}$, Ismassabah Ismail2, Nor Azida Mohamed Noh", \\ Anita Mohd Yasin ${ }^{1}$, Zainab Othman ${ }^{1}$ and Siti Nuur Atikah Che Yahaya ${ }^{1}$ \\ ${ }^{1}$ Faculty of Computer and Mathematical Sciences, UiTM Cawangan Melaka, Melaka, Malaysia \\ nurul417@uitm.edu.my; azida@fskm.uitm.edu.my; anitamy@fskm.uitm.edu.my; \\ zainab@melaka.uitm.edu.my; atikacy@gmail.com \\ ${ }^{2}$ Centre of Foundation Studies, UiTM Cawangan Selangor, Selangor Malaysia \\ isma@tmsk.uitm.edu.my \\ *Correspondence: nurul417@uitm.edu.my
}

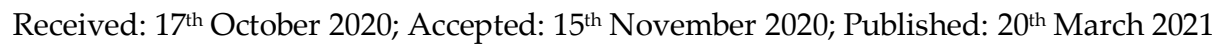

Abstract: The science includes a lot of concepts and abstract that cannot be seen by the naked eye. Students have a problem remembering and visualize information contained in the science subject. Hence, the idea of the development of effective visualization learning materials using Virtual Reality is expected. By using VR, the user can visualize the structure and interact with the components inside. The purpose of the present study was to evaluate the effectiveness of application in learning the Human Respiratory System through virtual reality (VR). The evaluation conducted among secondary school students by using the Kirkpatrick Model evaluation model. The data collected from 35 Form 3 students that take a science subject. The overall percentage average of the evaluation is $72 \%$, which considered $V$-HURESYS application was effective in learning the Human Respiratory System through the VR technique. Keenly, the results of the study will emphasize the student's performance in their science subject, especially in learning Human Respiratory System topics.
\end{abstract}

Keywords: Human Respiratory, Kirkpatrick Model, Science Subject, Virtual Reality

\section{Introduction}

Many students face problems during science subject classes [1]. Typically, to study something new in order to enhance one's knowledge, the students must possess the necessary information on the subject. Students must have the ability to differentiate between the knowledge that has already discovered and new areas of knowledge that should explore to become effective learners. Besides, to be able to learn effectively, the students must ensure that they can assess their knowledge, particularly in the areas of new advancement in knowledge such as science subjects. Students who can ultimately oversee their knowledge would be able to focus on their energy and time to learn the areas of knowledge that are yet to be researched by them [2]. The methods of teaching, as well as materials used to convey the knowledge, are both essential aspects required for the teaching and learning process. Both tools are fundamental in promoting teacher's competency and upgrade student's knowledge as well as capabilities.

However, many teachers still refuse to learn newly developed effective techniques, so when the techniques less used in classes, students are not able to benefit from it even though the techniques are proven to enhance students' performance. Prior research found that students

Nurul Hidayah Mat Zain, Ismassabah Ismail, Nor Azida Mohamed Noh, Anita Mohd Yasin, Zainab Othman and Siti Nuur Atikah Che Yahaya, "Virtual Learning for Human Respiratory System Via Non-Immersive VR (V-HURESYS): An Evaluation", Annals of Emerging Technologies in Computing (AETiC), Print ISSN: 2516-0281, Online ISSN: 2516-029X, pp. 86-93, Vol. 5, No. 5, $20^{\text {th }}$ March 2021, Published by International Association of Educators and Researchers (IAER), DOI: 10.33166/AETiC.2021.05.010, Available: http://aetic.theiaer.org/archive/v5/v5n5/p10.html. 
commonly fail their examinations due to a lack of proper teaching methods as well as the insufficiency of necessary teaching aids [3]. To name a few, among the instructional teaching aid used in effective teaching and learning is the Virtual Reality (VR) technique [4-7]. VR technique is a type of computer-generated simulations in a three-dimensional (3D) environment or image. The interactions can be almost real and physical when a person uses specific electronic tools installed with sensors (for example, helmet or gloves). A previous study [7-10] conducted on VR learning experiences among students, demonstrated a positive finding of VR simulation. It reflected in the improvements in prescribed structures of knowledge [11]. That study, which conducted on molecular biology, found that the exercise on visualization helped to conceptualize, initiate, and evaluate the understanding of the students' performance [11].

In science subjects such as biology, the students usually find it hard to understand because of the complicated concept, a biological process that cannot witness with the eyes, abstract concepts as well as terminologies which are foreign to the student's ears. Other than that, many students thought that memorizing is the only way to learn biology subjects in schools [12]. However, modern days teaching and learning have included various techniques to learn science subjects. One of the techniques is by using game-based learning [13, 14], as well as the VR approach [15]. Hence, the objective of this study is to evaluate the effectiveness of application in learning the Human Respiratory System through VR application.

\section{Background Study}

There are various types of evaluation models, such as Outcome-Based Evaluation (OBE) [16], CIPP Evaluation Model [17], as well as the Kirkpatrick Model [18, 19]. Stufflebeam introduced the CIPP Model in the year 1971. CIPP means the evaluations of an entity's Context, Input, Output, Process, and Products. The fundamental purpose of the evaluation is to stipulate the environment's availability to achieve the objectives and goals of the program. Moreover, the CIPP model helps the leader held the responsibilities by utilizing the source and the information to improve the program or the process. Outcome-based evaluation (OBE) means the evaluation based on the goals of the programs that should be achieved by the individuals who receive their services. The stakeholders outline the evaluation to reflect the organization's effectiveness as well as efficiency. The OBE concentrates on the benefits that can be gained by using the program. It also views whether the organizations' activities meet the client's demands.

On the other hand, the Kirkpatrick Model is used as the worldwide standard to evaluate a training's effectiveness [20, 21]. Various fields of training have adapted Kirkpatrick's model by utilizing four levels of evaluations. The objectives' level comprises outcome, performances, knowledge, as well as motivation, which is correlated to the current evaluation level of Reaction, Learning, Behavior as well as Result evaluations. The questionnaire is adapted based on the Kirkpatrick Model as well. Among the examples of adaptations of Kirkpatrick's model are in technical communication services and products such as the assessment of learning in higher education. Previous studies collected the data through a questionnaire and analyzed using descriptive statistics. As an example, the used of questionnaires as pre-quiz and post-quiz to evaluate trainees' learning effectiveness.

The model is used in this study to evaluate the effectiveness of the application. The usage is to guide the evaluations to determine if this application is effective and whether it reaches its objectives. Kirkpatrick's model uses four levels of evaluations, namely, Reaction, Learning, Behavior, and finally, Result evaluations. The respondents are required to answer three questionnaires during the experiment to gain feedback such as pre-test, post-test, and effectiveness testing. The pre-test and post-test conducted to evaluate the respondents' understanding of the topic of the Human Respiratory System. Next, the comparison between before and after using the $V$-HURESYS is made. Lastly, the effectiveness testing is done by utilizing the Kirkpatrick model for the final part of the experiment. However, only the findings of effectiveness testing will be discussed in this study. 


\section{Methodology}

\subsection{Participation}

The respondents selected to participate in this study are form three (Form 3) students in a secondary school who take science subjects. This project investigates the usage of non-immersive virtual reality for students to learn the Human Respiratory System. The target users were given three questionnaires as a pre-test before the actual testing of the application. After that, the post-test, as well as effectiveness testing, were conducted after the respondents used the application. The questionnaire was prepared in the Malay language (Bahasa Melayu) with simple instructions to ease the respondents in answering the questions. The experiment occurred at SMK Pak Badol, Kota Bharu Kelantan, where it managed to gather 35 students as respondents.

\subsection{Procedure}

During the experiment, the students stayed at one designated place provided by their teacher. All the students who participated in this study learned the topic of the Human Respiratory System in science class before they involved in the experiment. A brief explanation and demo are showed before the students start testing the application in order to ensure that students understand and make this testing process successfully. As the first step to test the application, the students were required to answer a set of pre-test questions about the Human Respiratory System. Students were provided with a laptop computer to play the application till the end. Figure 1 shows part of the scene in the application. Every student was given 5-8 minutes for each testing session. The students are given a post-test question on the subject of the Human Respiratory System as well as an effective survey question after finished testing the application. Pre-test questions were given to the respondents before the evaluation process started and after the regular teaching and learning process of the subject. The pre-test results were examined and recorded.

After the students using the application, post-tests were given to the target users. The pre and post-test questions are the same set of questions. The purpose of conducting pre-test and post-tests are to verify whether the application is effective in conveying the knowledge to the students, which is why the performance of the students was measured. The results of both pre-test and post-test were analyzed where the average percentage was obtained, compared, and plotted with a bar chart. The difference in average score between male and female respondents was conducted by comparing the average difference between pre and post-test scores by gender. This analysis is to understand whether gender influences in this study in terms of performance by the students.

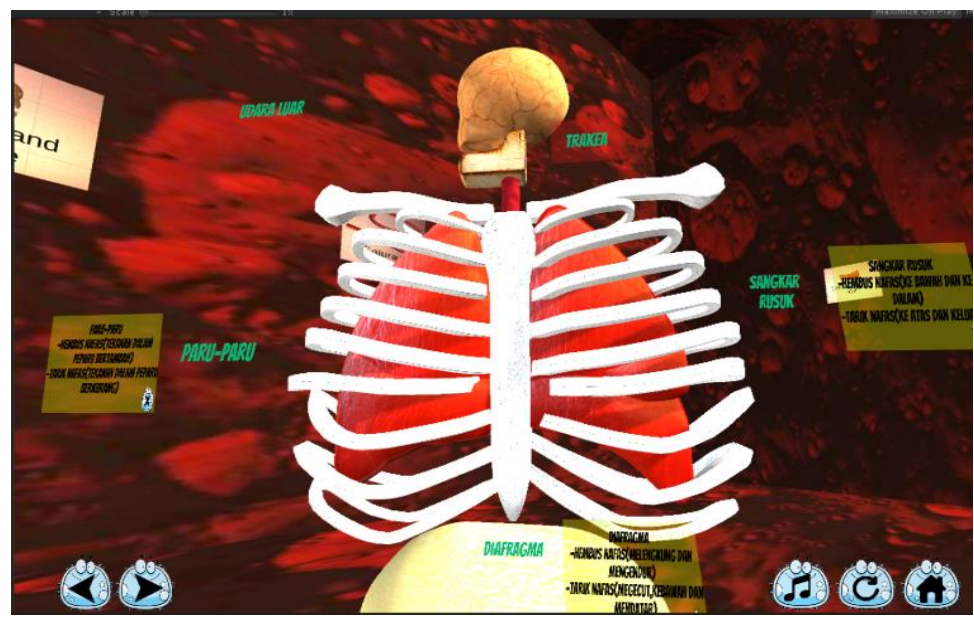

Figure 1. Part of the scene in the application

\subsection{Instrument}

The instrument to evaluate the respondents comprises three sets of the instrument, namely pre-test, post-test, to test if the respondents understand the V-HURESYS application, and the effectiveness test by using the Kirkpatrick model that has been adapted from these two resources 
$[19,22]$. The utilization of the instrument is a low cost yet an effective method to gain the information [23]. Apart from that, the benefit of using the instrument is because it is easy to handle, save time as well as low budget while collecting data. Among the information aimed at this instrument are achievement, understanding, interest, effectiveness, and how the students perceive this application. In the instrument, there are three elements of the effectiveness testing. Table 1 shows the item distribution.

Part A consists of questions on the respondent's data. Demographic information such as personal data, level, and gender retrieved in this section. Part B collects information on the respondents' knowledge on VR while for part $\mathrm{C}$, the questions intended to evaluate the Reaction, Learning, and Behavior of the respondents on the content and application. This study gathers the information on how the use of the V-HURESYS application can help the students in visualizing, memorizing, and building the students' character to be more active when they learn the Human Respiratory System. The survey using a questionnaire where the Likert scale used to investigate how the students agree with the statements.

Table 1. The questions (Malay and English version) with code as references

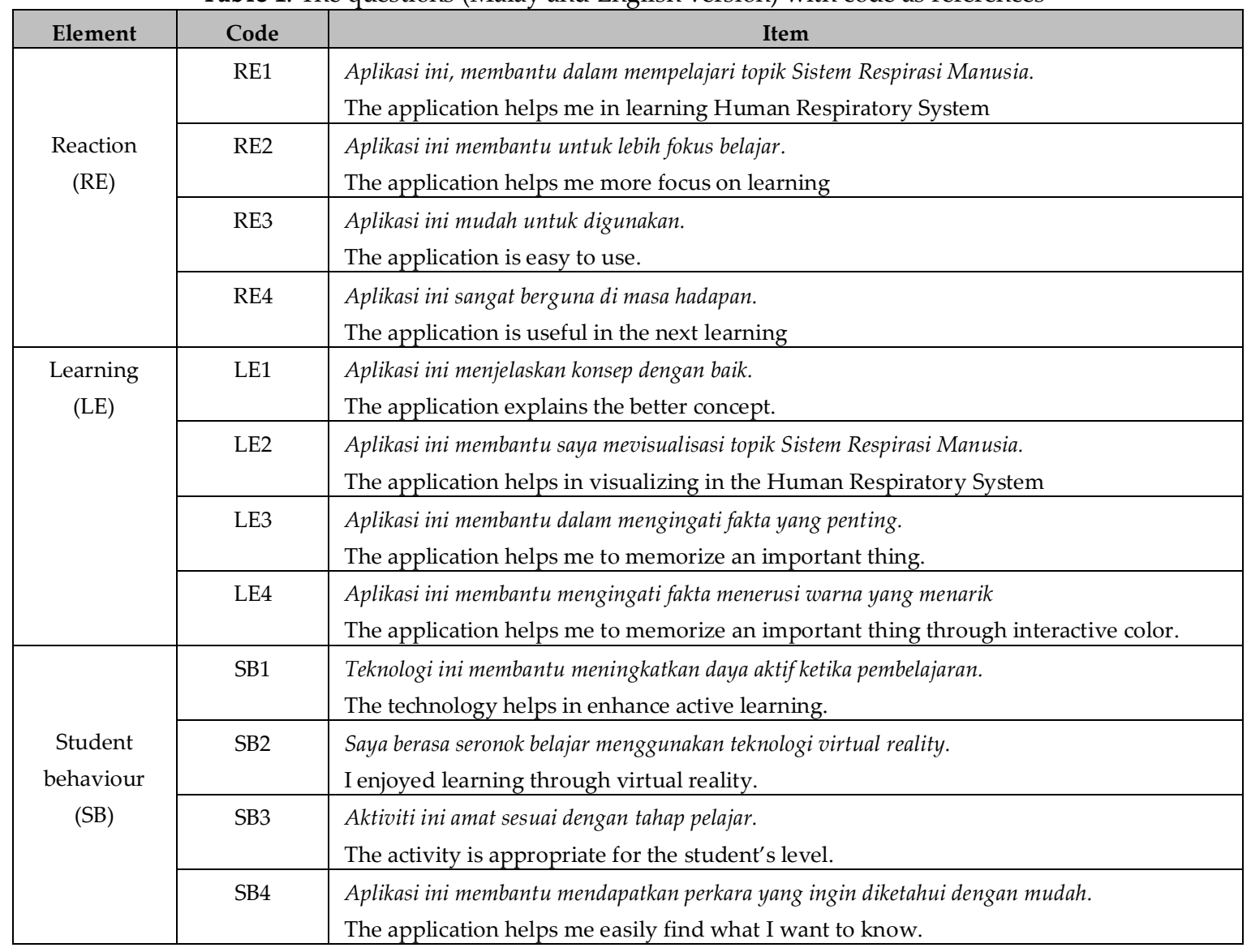

\section{Results}

This study aims to determine whether the V-HURESYS application using the VR approach is effective in the process of teaching and learning. The target user in this experiment consists of 18 female and 17 male students from Form 3 students who take science subjects in school. The selected students learned the topic of the Human Respiratory System in their class before the experiment. The testing was conducted in May 2018. The survey is given in the form of a Likert Scale from 1 to 5 (strongly disagree to strongly agree), whereas the pre-test and post-test examine the application contents that require the users to choose the most suitable answers. All the final results were collected and calculated. The scores from every set of pre-test, post-test, and effectiveness tests were summarized in the bar chart. In this paper, only the result of effectiveness testing is tabulated from 4.3, 4.4, and 4.5 using the Kirkpatrick model. 


\subsection{Respondent Background According to Gender}

As shown in Table 2, the Form 3 students who participated in this study are from a total of 17 male students (48.57\%) and 18 female students (51.43\%).

Table 2. Respondents distribution table by gender

\begin{tabular}{|c|c|c|}
\hline Gender & Frequency & Percentage (\%) \\
\hline Male & 17 & 48.57 \\
\hline Female & 18 & 51.43 \\
\hline Total & 35 & \\
\hline
\end{tabular}

\subsection{The Average Pre-test and Post-Test Percentage by Gender}

Table 3 shows that the average percentage of male students' in the pre-test is $56.15 \%$, while female respondents are $59.19 \%$. Meanwhile, the result of the post-test for male students is $72.47 \%$ and female students $79.11 \%$. The findings showed that gender does not influence in terms of performance by the students because of small differences between two categories of gender.

Table 3. The average pre and post percentage (\%) by gender

\begin{tabular}{|c|c|c|}
\hline Gender & Pre-Test (\%) & Post-Test (\%) \\
\hline Male & 56.15 & 72.47 \\
\hline Female & 59.19 & 79.11 \\
\hline
\end{tabular}

\subsection{Users' Reaction on Application}

Table 4 demonstrates the student's evaluation of the application by examining the students' reactions in the process of teaching and learning. From an overall analysis for four items in user's reactions towards application, it concludes that 54 (38.57\%) students strongly agree, $60(42.86 \%)$ students agree, 21 (15\%) students neutral, and $5(3.57 \%)$ students disagree about the application's suitability. The findings prove that most of the students exhibit a positive response towards the $V$ HURESYS application. It also shows that the application is suitable to explain the topic of the Human Respiratory System.

Table 4. Frequency of Users' Reaction

\begin{tabular}{|c|c|c|c|c|c|c|}
\hline Code & Strongly Agree & Agree & Neutral & Disagree & Strongly Disagree & Mean \\
\hline RE1 & 14 & 15 & 6 & 0 & 0 & 3.34 \\
\hline RE2 & 18 & 12 & 5 & 0 & 0 & 3.60 \\
\hline RE3 & 12 & 15 & 5 & 3 & 0 & 3.74 \\
\hline RE4 & 10 & 18 & 5 & 2 & 0 & 3.29 \\
\hline Total & 54 & 60 & 21 & 5 & 0 & - \\
\hline$\%$ & 38.57 & 42.86 & 15 & 3.57 & 0 & - \\
\hline \multicolumn{7}{|c|}{ Average mean } \\
\hline
\end{tabular}

\subsection{Users' Learning on Application}

Based on Table 5, it is discovered that 55 (39.29\%) students strongly agree, 58 (41.43\%) students agree, $23(16.43 \%)$ students neutral, and 4 (2.86 \%) students disagree with the question on the users' learning of the application based on the four items. The findings indicated that $V$ HURESYS could assist the students in this research to learn the topic of the Human Respiratory System with its usage of various colours as well as animation.

Table 5. Frequency of Users' Learning

\begin{tabular}{|c|c|c|c|c|c|c|}
\hline Code & Strongly Agree & Agree & Neutral & Disagree & Strongly Disagree & Mean \\
\hline LE1 & 21 & 7 & 7 & 0 & 0 & 3.77 \\
\hline LE2 & 19 & 12 & 4 & 0 & 0 & 3.84 \\
\hline LE3 & 10 & 18 & 5 & 2 & 0 & 3.82 \\
\hline LE4 & 5 & 21 & 7 & 2 & 0 & 3.59 \\
\hline Total & 55 & 58 & 23 & 4 & 0 & - \\
\hline$\%$ & 39.29 & 41.43 & 16.43 & 2.86 & 0 & - \\
\hline \multicolumn{7}{|c|}{ Average mean } \\
\hline
\end{tabular}




\subsection{Users' Behaviour on Application}

Table 6 demonstrate student's behaviour toward V-HURESYS application. The overall result from four items in user's behaviour found that 67 (47.86\%) strongly agree, 50 (35.71\%) agree, 22 $(15.72 \%)$ neutral, and $1(0.71 \%)$ disagree about the statements that related to the behaviour of respondents toward application. Most of the students are excited about using this application for Human Respiratory Learning.

Table 6. Frequency of Users' Behavior

\begin{tabular}{|c|c|c|c|c|c|c|}
\hline Code & Strongly Agree & Agree & Neutral & Disagree & Strongly Disagree & Mean \\
\hline UB1 & 12 & 13 & 10 & 0 & 0 & 3.55 \\
\hline UB2 & 15 & 12 & 8 & 0 & 0 & 3.70 \\
\hline UB3 & 21 & 10 & 3 & 1 & 0 & 3.93 \\
\hline UB4 & 19 & 15 & 1 & 0 & 0 & 3.06 \\
\hline Total & 67 & 50 & 22 & 1 & 0 & - \\
\hline$\%$ & 47.86 & 35.71 & 15.72 & 0.71 & 0 & - \\
\hline \multicolumn{6}{|c|}{ Average mean } & 3.56 \\
\hline
\end{tabular}

\section{Discussion}

The respondents comprise 17 male students (48.57\%) and 18 female students (51.43\%) of Form 3 students. The result of the analysis of pre-test and post-test by gender demonstrates that the male students' average pre-test score is $56.15 \%$, while the score for the post-test is $72.47 \%$. There is an increase of $16.32 \%$ in male respondents' achievement after they experienced the process of teaching and learning with the application. As for the female students, the result of the pre-test is $59.19 \%$, while the post-test score is $79.11 \%$. Hence, it is showed that the average increase in female students' scores is $19.92 \%$. The difference between male and female respondents are only $3.6 \%$ (male students $16.32 \%$, and $19.92 \%$ for females). The scenario result shows a small difference between gender. The result indicated that gender does not affect the performance before and after using the application in this study. The tabulation of the data in this research utilizes the IBM SPPSS software because it is the leading statistical software for solving various business and research problems. This research uses the Kirkpatrick's model, where the data collected through the questionnaires designed by using five Likert scales of different categories such as; Strongly Agree (SA), Agree (A), Neutral (N), Disagree (D) as well as strongly disagree (SD).

The mean of each category was summarized into total mean, which is shown in Table 7 to determine the part that shows the highest total mean in terms of Reaction, Learning, or Students' Behaviour towards the application. Table 7 demonstrates that the learning process, when utilizing the application, gained the highest total mean with 3.76 average values. Based on this finding, it is proven that the $V$-HURESYS application is a learning aid that is more effective in enhancing the students' understanding of the Human Respiratory System. Besides, the result showed students' behaviour towards the usage of the application, where the mean is 3.56. This finding is coherent with the aim of this research to assist the learning process to become more interactive so that the students will be able to understand and visualize the Human Respiratory System.

Table 7 demonstrates the learning process when utilizing the application gained the highest total mean with 3.75 average values. Based on this finding, it is proven that the V-HURESYS application is a learning aid that is more effective in enhancing the students' understanding of the Human Respiratory System. Besides, the result showed students' behavior towards the usage of the application, where the mean is 3.56. This finding is coherent with the aim of this research to assist the learning process to become more interactive so that the students will be able to understand and visualize the Human Respiratory System.

Moreover, 3.49 average value shows that the students in this study provided positive feedback on the V-HURESYS application as teaching aid in acquiring knowledge in the Human Respiratory System using VR. Finally, the mean value for the overall average is 3.60 or $72 \%$, which demonstrates that respondents agree that $V$-HURESYS application is effective to be used in gaining knowledge about the Human Respiratory System. 
Table 7. Total mean for each category

\begin{tabular}{|c|c|}
\hline Element & Total Mean \\
\hline Reaction & 3.49 \\
\hline Learning & 3.76 \\
\hline User behaviour & 3.56 \\
\hline Overall Total Mean & $\mathbf{3 . 6 0}$ \\
\hline \% of Overall Total Mean & $\mathbf{( 3 . 6 0 / 5 )} * \mathbf{1 0 0}=\mathbf{7 2} \%$ \\
\hline
\end{tabular}

\section{Conclusion}

This study uses the Kirkpatrick model to evaluate because it is most suitable to examine the application's effectiveness using the survey as well as a pre-test and post-test questions. According to the evaluation result, it proves that the $V$-HURESYS application is effective in helping students to learn about the Human Respiratory System. The study discovered that 39.29\% of the respondents strongly agree, while $41.43 \%$ agree with the statement in the questionnaire related to the learning part. Apart from that, the result indicates the overall percentage of the average of the evaluation is $72 \%$, which indicated the effectiveness of V-HURESYS application in helping students to learn the Human Respiratory System via VR technique. As for the future study, the recommendation of this study can be considered to improve limitations to make the application more reliable and functional to the user.

\section{Acknowledgments}

We would like to express truthful thanks for the Ministry of Higher Education Malaysia for sponsoring this research by using the funding of the Fundamental Research Grant Scheme (FRGS) numbered 600-IRMI/FRGS 5/3 (210/2019). We also are incredibly grateful to all of the respondents who were directly or indirectly involved in this study.

\section{References}

[1] Millar R. (1991). Why Is Science Hard to Learn? Journal of Computer assisted learning. Vol. 7, No. 2, PP. 66-74. Available: https://onlinelibrary.wiley.com/doi/abs/10.1111/j.1365-2729.1991.tb00229.x.

[2] Ziegler B., Montplaisir L. (2014). Student Perceived and Determined Knowledge of Biology Concepts in an Upper-Level Biology Course. CBE Life Sci Educ. Vol. 13, No. 2, PP. 322-330. Available: https://pubmed.ncbi.nlm.nih.gov/26086662.

[3] Olayinka A. R. B. (2016). Effects of Instructional Materials on Secondary Schools Students' Academic Achievement in Social Studies in Ekiti State, Nigeria. World Journal of Education. Vol. 6, No. 1, PP. 32-39.

[4] Lee R. M., Jacob C., Sharkey K. A. (2019). The Mind-Gut Connection: A Virtual Reality Education Program on the Relationship between the Digestive System, Nervous System, and Microbiome.

[5] Balsam P., Borodzicz S., Malesa K., Puchta D., Tymińska A., Ozierański K., Kołtowski Ł., Peller M., Grabowski M., Filipiak K. J. (2019). Oculus Study: Virtual Reality-Based Education in Daily Clinical Practice. Cardiology journal. Vol. 26, No. 3, PP. 260-264.

[6] Ammanuel S., Brown I., Uribe J., Rehani B. (2019). Creating 3d Models from Radiologic Images for Virtual Reality Medical Education Modules. Journal of medical systems. Vol. 43, No. 6, PP. 166.

[7] Bogusevschi D., Muntean C., Muntean G.-M. (2020). Teaching and Learning Physics Using 3d Virtual Learning Environment: A Case Study of Combined Virtual Reality and Virtual Laboratory in Secondary School. Journal of Computers in Mathematics and Science Teaching. Vol. 39, No. 1, PP. 5-18.

[8] Liu D., Bhagat K. K., Gao Y., Chang T.-W., Huang R. (2017). Virtual, Augmented, and Mixed Realities in Education. Springer. pg. 105-130.

[9] Vesisenaho M., Juntunen M., Häkkinen P., Pöysä-Tarhonen J., Fagerlund J., Miakush I., Parviainen T. (2019). Virtual Reality in Education: Focus on the Role of Emotions and Physiological Reactivity. Journal of Virtual Worlds Research. Vol. 12, No. 1, PP. Available: http://urn.fi/URN:NBN:fi:jyu-201902111469.

[10] Monita F., Ikhsan J. (2020). Development Virtual Reality Ipa (Vr-Ipa) Learning Media for Science Learning. Journal of Physics: Conference Series. UK.

[11] Tan S., Waugh R. (2013). 3d Immersive and Interactive Learning. Springer. pg. 17-43.

[12] Cimer A. (2012). What Makes Biology Learning Difficult and Effective: Students' Views. Educational Research and Reviews. Vol. 7, No. 3, PP. 61. Available: http://www.academicjournals.org/ERR. 
[13] Rozaidi S., Ismail I. (2018). Enjoyment of Learning Biology through Mobile Game Based Learning for Form 5 Students: Kidney Rush. 1st Information, Communication and Multimedia Technology Colloquium (ICMMTC), PP. 163-170,

[14] Zeng H., Zhou S.-N., Hong G.-R., Li Q.-y., Xu S.-Q. (2020). Evaluation of Interactive Game-Based Learning in Physics Domain. Journal of Baltic Science Education. Vol. 19, No. 3, PP. 484-498. Available: http://www.scientiasocialis.lt/jbse/files/pdf/vol19/484-498.Zeng_JBSE Vol.19_No.3.pdf.

[15] N. Idayu B. J., and A. A. Aziz,. (2018). Vrelestia: Acquiring Knowledge of Planets and Constellations in Immersive Virtual Reality for Kids. 1st Information, Communication and Multimedia Technology Colloquium (ICMMTC), PP. 398-404,

[16] Schalock R. L. (2001). Outcome-Based Evaluation. Springer US. pg.

[17] Stufflebeam D. L. (1971). The Relevance of the Cipp Evaluation Model for Educational Accountability. Annual meeting of the American Association of School Administrators. pg. 30.

[18] Smidt A., Balandin S., Sigafoos J., Reed V. A. (2009). The Kirkpatrick Model: A Useful Tool for Evaluating Training Outcomes. Journal of Intellectual and Developmental Disability. Vol. 34, No. 3, PP. 266-274.

[19] Kirkpatrick J. D., Kirkpatrick W. K. (2016). Kirkpatrick's Four Levels of Training Evaluation. Association for Talent Development.

[20] Paull M., Whitsed C., Girardi A. (2016). Applying the Kirkpatrick Model: Evaluating An'interaction for Learning Framework'curriculum Intervention. Issues in Educational Research. Vol. 26, No. 3, PP. 490-501. Available: http://clt.curtin.edu.au/events/conferences/tlf/tlf2016/refereed/paull.pdf.

[21] Lin J., Cantoni L. (2017). Information and Communication Technologies in Tourism 2017. Springer. pg. 129-142.

[22] Fregonese C., Caputo A., Langher V. (2018). Italian Translation of the Questionnaire for Professional Training Evaluation. International Journal of Training and Development. Vol. 22, No. 1, PP. 34-50. Available: https://core.ac.uk/download/pdf/141694623.pdf.

[23] Zain N. H. M., Johar R. H., Aziz A. A., Baharum A., Jaafar A., Yasin A. M. (2017). An Evaluation of Player Enjoyment in Game-Based Learning Arithmetic Drills Via Racing Game. International Visual Informatics Conference.

(C) 2021 by the author(s). Published by Annals of Emerging Technologies in Computing (AETiC), under the terms and conditions of the Creative Commons Attribution (CC BY) license which can be accessed at http://creativecommons.org/licenses/by/4.0. 